\title{
Efeito da compactação do solo no desenvolvimento aéreo e radicular de cultivares de milho(1)
}

\author{
José Salvador Simoneti Foloni(2), Juliano Carlos Calonego( ${ }^{(2)}$ e Sérgio Lázaro de Lima(3)
}

\begin{abstract}
Resumo - O objetivo deste trabalho foi avaliar o desenvolvimento aéreo e radicular de duas cultivares de milho (Zea mays L.), em solo submetido a quatro níveis de compactação. Utilizou-se um Latossolo Vermelho-Escuro distroférrico de textura média, em vasos montados com anéis de PVC sobrepostos, com diâmetro interno de $14,5 \mathrm{~cm}$ e altura de $35 \mathrm{~cm}$. Os níveis de compactação utilizados em subsuperfície foram caracterizados pelas densidades do solo de 1,28, 1,42, 1,56 e 1,69 $\mathrm{Mg} \mathrm{m}^{-3}$. As cultivares de milho foram o híbrido AG-5011 e a variedade Sol da Manhã. Aos 40 dias após a emergência das plantas, determinaram-se as massas da matéria seca da parte aérea e das raízes, a densidade do comprimento radicular e o diâmetro médio radicular. A compactação do solo comprometeu o desenvolvimento das plantas de milho híbrido e da variedade na mesma intensidade. Apesar de alterar a distribuição do sistema radicular ao longo do perfil do solo, o impedimento físico em subsuperfície não diminuiu a produção total de raízes de milho. O diâmetro médio radicular apresentou alta correlação com o crescimento de raízes no solo compactado. O sistema radicular do milho não é capaz de romper uma camada compactada de solo com resistência mecânica da ordem de 1,4 MPa.
\end{abstract}

Termos para indexação: Zea mays, cultivar, sistema radicular, densidade do solo, mecânica do solo.

\section{Effect of soil compaction on shoot and root growth of maize cultivars}

Abstract - The objective of this study was to evaluate shoot and root development of two cultivars of maize (Zea mays L.) (the hybrid AG-5011 and the variety Sol da Manhã), in soil submitted to four different levels of compaction. Plants were grown in pots with a medium texture distroferric Red Latosol. The pots were built with three rings of PVC superposed, with $14.5 \mathrm{~cm}$ internal diameter and $35 \mathrm{~cm}$ high, and the bulk density of the subsoil layer was adjusted for $1.28,1.42,1.56$ and $1.69 \mathrm{Mg} \mathrm{m}^{-3}$. Forty days after plant emergence, plants were assessed for the amount of shoot and root dry matter, root length density and root mean diameter. Soil compaction compromised both hybrid and variety, at the same intensity. In spite of altering the root system distribution along the soil profile, the subsoil physical impediment did not reduce total maize root production. Root mean diameter showed high correlation with root growth within the compaction soil layer. Roots of maize are not able to break compacted soil layer with 1.4 MPa of penetrometer resistance.

Index terms: Zea mays, cultivars, root systems, soil density, soil mechanics.

\section{Introdução}

Os fatores do solo que afetam o desenvolvimento radicular podem ser divididos em fatores químicos, como nutrientes e elementos tóxicos, e fatores

\footnotetext{
(1) Aceito para publicação em 13 de maio de 2003.

Trabalho apresentado no XXIV Congresso Nacional de Milho e Sorgo.

${ }^{(2)}$ Universidade Estadual Paulista (Unesp), Faculdade de Ciências Agronômicas (FCA), Caixa Postal 237, CEP 18603-970 Botucatu, SP. Bolsista da Fapesp. E-mail: sfoloni@fca.unesp.br, jcalonego@hotmail.com.br

${ }^{(3)}$ Unesp, FCA. E-mail: secdcs@fca.unesp.br
}

físicos, como resistência mecânica à penetração, disponibilidade hídrica e aeração (Rosolem, 1995).

Quando um solo não saturado é submetido a determinada pressão, ocasionando redução de volume com conseqüente aumento de densidade, ocorre o processo de compactação do solo (Gupta \& Allmaras, 1987). O arranjo estrutural do solo, a consistência, a porosidade total, o número e tamanho dos poros e a difusão de gases são afetados pela compactação, que, por consequiência, afeta o crescimento das raízes (Taylor \& Brar, 1991). Em termos práticos, o uso intensivo de máquinas, segundo Camargo \& Alleoni (1997), vem tornando comuns os problemas de compactação em solos agrícolas. 
O alongamento radicular só é possível quando a pressão de crescimento das raízes for maior do que a resistência mecânica do solo à penetração (Passioura, 1991). Segundo Russel \& Goss (1974), a pergunta a ser feita seria qual a impedância mecânica máxima do solo suportável para que não haja prejuízos à produção agrícola. Silva et al. (2002) relatam que um valor de $2 \mathrm{MPa}$ de resistência à penetração do solo tem sido associado a condições impeditivas para o crescimento das raízes e da parte aérea das plantas.

De acordo com Materechera et al. (1992), a resistência mecânica do solo causa aumento do diâmetro das raízes na camada compactada por provocar modificações morfológicas e fisiológicas, específicas a cada espécie ou cultivar, a fim de se adaptarem. As raízes diminuem de diâmetro para penetrar pequenos poros, pois a resistência mecânica do solo estimula a proliferação de raízes laterais, as quais são mais finas (Russel \& Goss, 1974). Portanto, existe uma estreita relação entre porosidade do solo e crescimento radicular, com crescimento de raízes maior onde há maior número e continuidade de macroporos (Hatano et al., 1988).

Rosolem et al. (1994b) mostraram que a compactação do solo afetou o crescimento radicular, mas não afetou a produção de matéria seca total e a parte aérea de plantas de milho. Gediga (1991) constatou que, em níveis considerados intermediários de compactação do solo, houve incrementos no acúmulo de massa na parte aérea do milho. Para Bennie (1996), é difícil generalizar conclusões, pois a influência da compactação do solo sobre o crescimento radicular é decorrente de diversos fatores, que dependem das características genéticas das plantas, das condições ambientais e do estádio de desenvolvimento do vegetal.

Com relação às diferenças genéticas do milho, Paterniani (1993) relata que tanto híbridos como variedades apresentam vantagens e limitações. $\mathrm{O}$ autor argumenta que, na prática, o milho híbrido só produz resultados notáveis em países desenvolvidos, onde o nível tecnológico e as condições climáticas são favoráveis. Por outro lado, nos países menos desenvolvidos, especialmente de clima tropical e subtropical, nem sempre tem sido possível demonstrar a superioridade do híbrido. Para Silva \& Corrêa (1990), as varieda- des de milho apresentam custo baixo de sementes e podem apresentar maior estabilidade de produção, porém, são inferiores aos híbridos em rendimento de grãos e uniformidade de plantas.

O objetivo deste trabalho foi avaliar o desenvolvimento aéreo e radicular de duas cultivares de milho com características genéticas distintas, em solo submetido a quatro níveis de compactação.

\section{Material e Métodos}

O experimento foi conduzido em casa de vegetação do Departamento de Recursos Naturais-Ciência do Solo, da Faculdade de Ciências Agronômicas - Unesp, em Botucatu, SP. O solo utilizado foi coletado de 0 a $20 \mathrm{~cm}$ de profundidade em um Latossolo Vermelho distroférrico (Carvalho et al., 1983; Embrapa, 1999) de textura média (615 $\mathrm{g} \mathrm{kg}^{-1}$ de areia, $45 \mathrm{~g} \mathrm{~kg}^{-1}$ de silte e $340 \mathrm{~g} \mathrm{~kg}^{-1}$ de argila). $\mathrm{O}$ solo foi secado ao ar e passado em peneira com malha de $2 \mathrm{~mm}$. A análise química (Raij \& Quaggio, 1983) revelou os seguintes valores: $\mathrm{pH}\left(\mathrm{CaCl}_{2}, 0,1 \mathrm{M}\right) 4,3$; 2,0 mg dm${ }^{-3}$ de $\mathrm{P}_{\text {resina }} ; 16 \mathrm{~g} \mathrm{dm}^{-3} \mathrm{de} \mathrm{MO}_{7}$ 73, $0 \mathrm{mmol}_{\mathrm{c}} \mathrm{dm}^{-3}$ de $\mathrm{H}+\mathrm{Al} ; 0,3 \mathrm{mmol}_{\mathrm{c}} \mathrm{dm}^{-3}$ de $\mathrm{K} ; 5,5 \mathrm{mmol}_{\mathrm{c}} \mathrm{dm}^{-3}$ de $\mathrm{Ca}$; $1,0 \mathrm{mmol}_{\mathrm{c}} \mathrm{dm}^{-3}$ de $\mathrm{Mg} ; 6,8 \mathrm{mmol}_{\mathrm{c}} \mathrm{dm}^{-3}$ de $\mathrm{SB}$; $79,8 \mathrm{mmol}_{\mathrm{c}} \mathrm{dm}^{-3}$ de CTC e $8,5 \%$ de saturação por bases (V). $\mathrm{O}$ pH do solo foi corrigido com calcário dolomítico (CaO: 28\%, MgO: 20\% e PRNT: 95\%) para que a saturação por bases fosse elevada a $70 \%$. Após a calagem, as amostras de solo foram umedecidas à capacidade de campo e acondicionadas em sacos de plástico por 30 dias. Passado esse tempo, foram adicionados $100 \mathrm{mg} \mathrm{dm}^{-3} \mathrm{de} \mathrm{N}$ (uréia), $200 \mathrm{mg} \mathrm{dm}^{-3}$ de $\mathrm{P}$ (superfosfato simples) e $150 \mathrm{mg} \mathrm{dm}^{-3}$ de $\mathrm{K}$ (cloreto de potássio). O ponto máximo de retenção de água do solo desestruturado (peneirado) foi determinado a -0,03 MPa no aparelho extrator de Richards (Embrapa, 1997), e o valor encontrado foi de $169 \mathrm{~g} \mathrm{~kg}^{-1}$ de água.

Foram montadas colunas com três anéis de PVC sobrepostos, com diâmetro interno de $14,5 \mathrm{~cm}$. A altura do anel superior era de $10 \mathrm{~cm}$, a do inferior, $20 \mathrm{~cm}$, e do anel intermediário, em que se localizaram os diferentes níveis de compactação, de $5 \mathrm{~cm}$. Os anéis foram unidos com fita adesiva. Com o intuito de evitar o crescimento de raízes entre a parede interna do anel intermediário e o solo, antes da montagem das colunas, foram colocadas fitas adesivas de plástico de cerca de 2,0 cm de largura dobradas da periferia para o centro da superfície superior da camada compactada, conforme método descrito por Müller et al. (2001). Essas fitas funcionaram como uma barreira para o crescimento de raízes em pontos de menor resistência 
mecânica à penetração, ou seja, na interface PVC-solo compactado.

Para preparar os anéis da camada compactada, foram separadas porções de solo fertilizado que tiveram o teor de água e a massa determinados. Na seqüência, corrigiu-se a umidade do solo a $135 \mathrm{~g} \mathrm{~kg}^{-1}$ (correspondente a $80 \%$ da máxima capacidade de retenção de água do solo). Em seguida, as porções de solo foram submetidas a uma prensa hidráulica desenvolvida por Foloni (1999), que permitiu atingir três níveis de compactação do solo utilizados no experimento. $\mathrm{O}$ tratamento testemunha (nível zero de compactação) foi obtido por meio do preenchimento dos anéis intermediários com solo sem prensagem.

Os níveis de compactação do solo foram definidos por meio de um ensaio preliminar, com quatro repetições, onde foram colocados anéis de aço (diâmetro interno de $40 \mathrm{~mm}$ e altura de $25 \mathrm{~mm}$ ) dentro da massa de solo que sofreu prensagem, para determinar a densidade do solo pelo método do anel volumétrico (Embrapa, 1997). A resistência mecânica do solo à penetração, correspondente aos níveis de compactação selecionados, foi determinada com um penetrômetro de bolso com ponteira cônica (base do cone de $18 \mathrm{~mm}$, altura de $40 \mathrm{~mm}$ e ângulo do vértice de $23^{\circ}$ ). Os resultados da impedância mecânica do solo foram de $0,09 \pm 0,029,0,39 \pm 0,052,0,72 \pm 0,051$ e $1,4 \pm 0,070 \mathrm{MPa}$ correspondentes às densidades do solo de $1,28 \pm 0,035$, $1,42 \pm 0,014,1,56 \pm 0,009$ e $1,69 \pm 0,012 \mathrm{Mg} \mathrm{m}^{-3}$, respectivamente.

As cultivares de milho (Zea mays L.) avaliadas foram o híbrido triplo AG-5011 da empresa Agroceres e a variedade Sol da Manhã da Embrapa. Colocaram-se cinco sementes por vaso, deixando-se, após cinco dias da emergência, duas plantas por vaso que foram cultivadas por 40 dias. A umidade do solo foi controlada diariamente por meio de pesagem dos vasos e reposição da água evapotranspirada até $169 \mathrm{~g} \mathrm{~kg}^{-1}$.
Após o período de cultivo, as raízes foram divididas por camada dos vasos (superior, compactada e inferior), e separadas do solo por lavagem com jatos de água dirigidos sobre peneiras de plástico com 0,5 e 0,25 mm de malha. As raízes foram acondicionadas em recipientes, submersas em solução aquosa com $30 \%$ de álcool etílico. A parte aérea das plantas foi secada em estufa a $60^{\circ} \mathrm{C}$ por 72 horas, e posteriormente pesada. Imagens das raízes foram digitalizadas em um scanner de leitura ótica na resolução de 250 dpi e analisadas pelo programa "Win Mac Rhizo", versão 3.8 (Regente Instrument Inc., Quebec, Canadá). Avaliaram-se as variáveis densidade do comprimento radicular ( $\mathrm{cm}$ raiz $\mathrm{cm}^{-3}$ de solo) e diâmetro médio radicular $(\mathrm{mm})$. Posteriormente, as raízes foram secadas em estufa a $60^{\circ} \mathrm{C}$ por 48 horas e tiveram suas massas determinadas.

O delineamento experimental adotado foi o de blocos ao acaso, num esquema fatorial $2 \times 4$ (duas cultivares de milho e quatro níveis de compactação do solo), com quatro repetições. Os dados originais foram comparados por meio de análise de variância e teste de médias (teste t). Fez-se também análise de regressão e foram consideradas as equações significativas a 5\% pelo teste F, com maior coeficiente de determinação. Os estudos estatísticos seguiram procedimentos descritos por Pimentel-Gomes (1990).

\section{Resultados e Discussão}

A compactação do solo influenciou todas as variáveis avaliadas, menos a produção total de raízes e o diâmetro médio radicular acima da camada de solo compactado (Tabela 1). Contudo, não houve diferença entre as cultivares de milho na resposta ao aumento da restrição física do solo. Característica inerente às variedades de milho, a maior adaptabili-

Tabela 1. Valores de F calculados pela análise de variância para a densidade do comprimento radicular, massa da matéria seca de raízes e diâmetro médio radicular nas camadas superior (S), compactada (C) e inferior (I) dos vasos, massa da matéria seca total de raízes e massa da matéria seca da parte aérea das plantas de milho.

\begin{tabular}{|c|c|c|c|c|c|c|c|c|c|c|c|}
\hline \multirow[t]{2}{*}{ Causas da variação } & \multicolumn{3}{|c|}{$\begin{array}{c}\text { Densidade de } \\
\text { comprimento radicular }\end{array}$} & \multicolumn{3}{|c|}{ Massa radicular } & \multicolumn{3}{|c|}{ Diâmetro médio radicular } & \multirow{2}{*}{$\begin{array}{c}\text { Massa } \\
\text { radicular } \\
\text { total }\end{array}$} & \multirow{2}{*}{$\begin{array}{c}\text { Massa da } \\
\text { parte } \\
\text { aérea }\end{array}$} \\
\hline & $\mathrm{S}$ & $\mathrm{C}$ & $\mathrm{I}$ & $\mathrm{S}$ & $\mathrm{C}$ & I & $\mathrm{S}$ & $\mathrm{C}$ & I & & \\
\hline Compactação do solo & $9,44 * *$ & $25,42 * *$ & $14,80 * *$ & $9,00 * *$ & $36,58 * *$ & 22,09 ** & 0,20 & $11,18^{* *}$ & 0,27 & 0,27 & $3,25^{*}$ \\
\hline Cultivares de milho & 0,04 & 3,68 & 0,002 & 0,05 & 0,24 & 0,04 & 2,67 & 0,58 & 0,98 & 0,0001 & 4,17 \\
\hline Compactação $\mathrm{x}$ cultivares & 1,91 & 1,81 & 0,93 & 1,39 & 2,02 & 0,54 & 1,46 & 2,21 & $3,66 *$ & 0,81 & 1,37 \\
\hline $\mathrm{CV}(\%)$ & 31,66 & 35,65 & 49,97 & 27,22 & 30,52 & 37,55 & 16,87 & 11,28 & 11,65 & 27,82 & 18,62 \\
\hline $\mathrm{DMS}^{(1)}$ & 3,01 & 0,57 & 1,19 & $\begin{array}{r}0,40 \\
0,40\end{array}$ & 0,05 & 0,16 & - & 0,04 & 0,04 & - & 1,61 \\
\hline Média Geral & 9,15 & 1,55 & 2,30 & 1,37 & 0,17 & 0,40 & 0,26 & 0,37 & 0,30 & 2,00 & 8,31 \\
\hline
\end{tabular}

${ }^{(1)}$ Diferença mínima significativa pelo teste t, a $5 \%$ de probabilidade. * e **Significativo a $5 \%$ e a $1 \%$ de probabilidade, respectivamente. 
dade a condições adversas do ambiente (Paterniani, 1993), que no presente trabalho decorreu da compactação do solo, não foi observada no caso da variedade Sol da Manhã.

A redução do crescimento aéreo das plantas de milho foi, em média, de aproximadamente $20 \%$, após 40 dias de cultivo sob 1,4 MPa de impedância mecânica do solo em subsuperfície (Figura 1). Silva \& Rosolem (2001) verificaram que o crescimento aéreo do sorgo granífero foi reduzido em mais de $40 \%$ ao final de 38 dias de cultivo, com uma resistência mecânica do solo da ordem de 1,22 MPa. Em contrapartida, no trabalho de Rosolem et al.
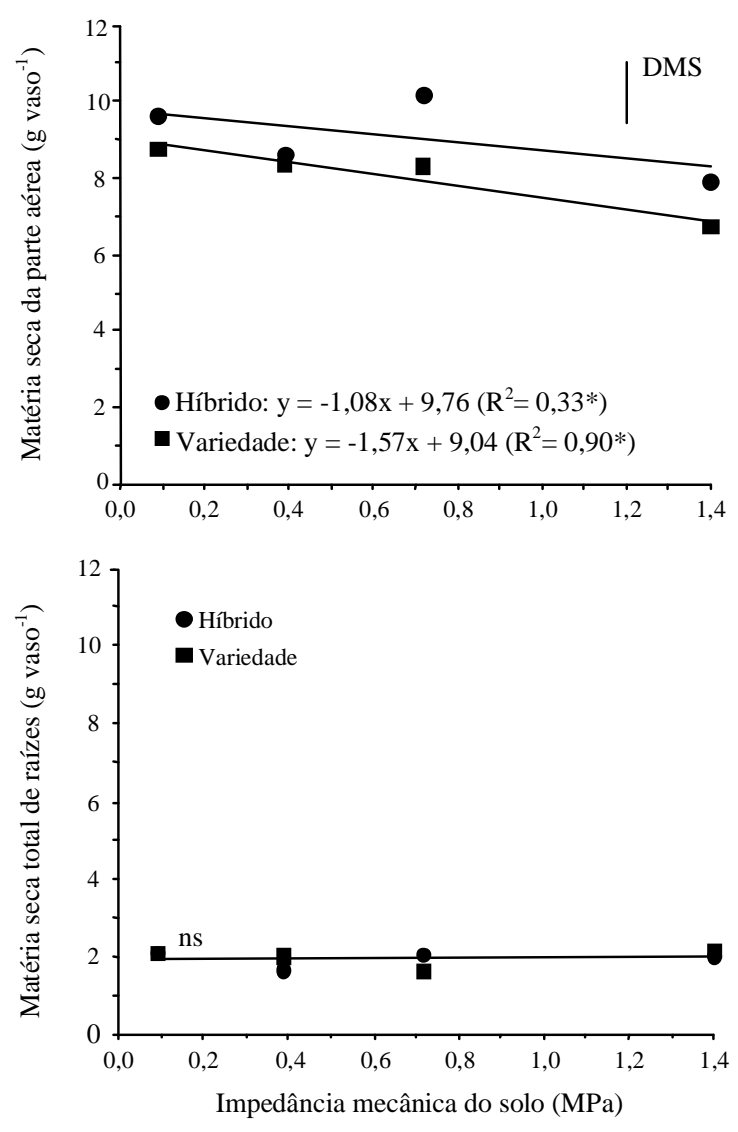

Figura 1. Matéria seca da parte aérea e matéria seca total de raízes das plantas de milho em função da impedância mecânica do solo. DMS: diferença mínima significativa pelo teste t, a 5\% de probabilidade. ${ }^{\text {ns }}$ Não-significativo. *Significativo a $5 \%$ de probabilidade. (1994b) não houve redução da parte aérea do milho submetido a 2 MPa de impedância mecânica do solo, colhido com 25 dias após a emergência das plântulas. Segundo Gediga (1991), a matéria seca da parte aérea do milho foi incrementada em $10 \%$ quando aumentou-se a densidade do solo de 1,45 para $1,70 \mathrm{Mg} \mathrm{m}^{-3}$ em subsuperfície. Os resultados desses trabalhos são contraditórios, no entanto, tudo indica que o estádio de desenvolvimento das plantas, por ocasião da avaliação, e a condição de cultivo influenciaram a resposta do crescimento vegetativo aéreo, o que reforça os relatos de Bennie (1996) sobre a dificuldade de se generalizar conclusões quanto ao desenvolvimento das plantas em solos compactados.

A soma das massas da matéria seca das raízes das camadas superior, compactada e inferior dos vasos não foi alterada com o aumento da impedância mecânica do solo (Figura 1). Portanto, a camada compactada em subsuperfície modificou a distribuição do sistema radicular ao longo do perfil do solo (Figura 2), mas não diminuiu a produção de raízes. No trabalho de Rosolem et al. (1994b), a compactação do solo inibiu o crescimento radicular do milho na camada compactada, porém levou a um maior crescimento na camada superficial, de maneira que, mesmo no maior nível de impedância mecânica do solo, não houve, no total, menos raízes que no menor nível de compactação, o que também foi constatado neste trabalho. Desta forma, a variável matéria seca total de raízes não foi adequada para aferir a sensibilidade das plantas de milho à compactação do solo.

Segundo Dexter (1987), o Q $1 / 2$ é o valor de resistência mecânica do solo à penetração, medido com penetrômetro, em que o crescimento radicular é reduzido à metade do máximo. $\mathrm{O} \mathrm{Q}_{1 / 2}$ médio das raízes das duas cultivares de milho na camada de solo compactada foi de $0,75 \mathrm{MPa}$ (Figura 2). No trabalho de Rosolem et al. (2002), os $\mathrm{Q}_{1 / 2}$ de plantas de milheto, sorgo, crotalária e girassol, na camada de solo compactado, foram de 0,73, 0,30, 0,97 e 0,86 MPa, respectivamente. $\mathrm{O} \mathrm{Q}_{1 / 2}$ da soja, determinado por Rosolem et al. (1994a), foi de 0,69 MPa. Portanto, as plantas de milho avaliadas no presente trabalho mostraram sensibilidade à compactação do solo semelhante a de espécies comumente utilizadas em sistemas de rotação de culturas, como a soja e o milheto. 
O nível crítico de impedância mecânica do solo foi de 1,4 MPa, ou seja, nesta condição de resistência à penetração, não houve crescimento radicular das plantas de milho abaixo da camada de solo compactado (Figura 2). Em contrapartida, Rosolem et al. (1994b) constataram que houve crescimento radicular do milho mesmo com $2 \mathrm{MPa}$ de resistência à penetração na camada de solo compactado. Silva et al. (2002) definem o valor de $2 \mathrm{MPa}$ de impedância mecânica do solo como restritivo ao crescimento radicular, contudo, os autores relatam que é necessário relacionar a resistência mecânica do solo à pe- netração com a aeração e com o potencial matricial de água do solo, para melhor compreender as restrições causadas pela compactação.

O diâmetro médio radicular das plantas de milho aumentou significativamente na camada de solo compactado com o aumento da resistência mecânica à penetração (Figura 2). Rosolem et al. (1994b) também constataram que houve engrossamento das raízes de milho dentro da massa de solo compactado. Na Figura 3, apresenta-se uma curva de correlação entre as variáveis densidade do comprimento radicular e diâmetro médio radicular na camada
Camada superior
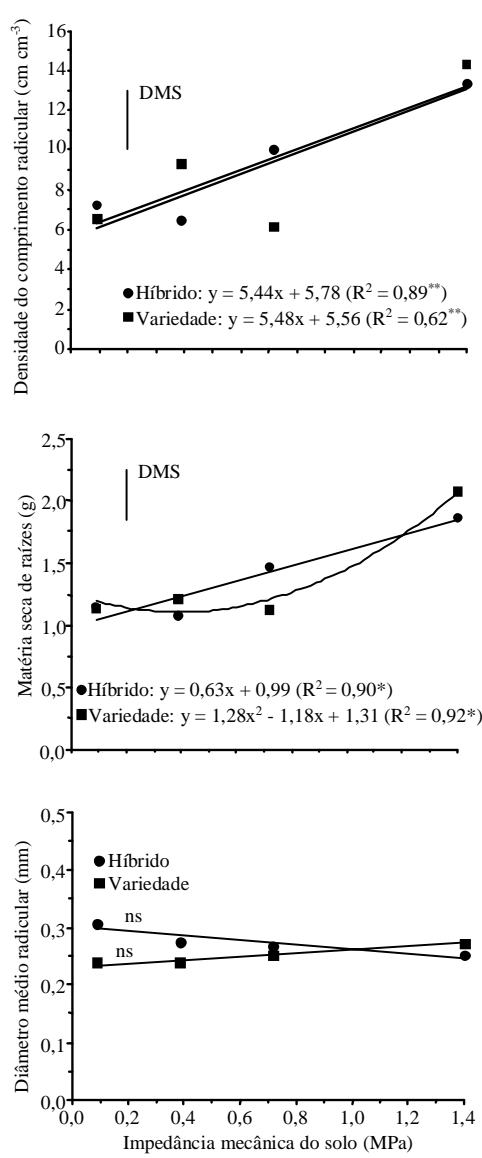

Camada compactada
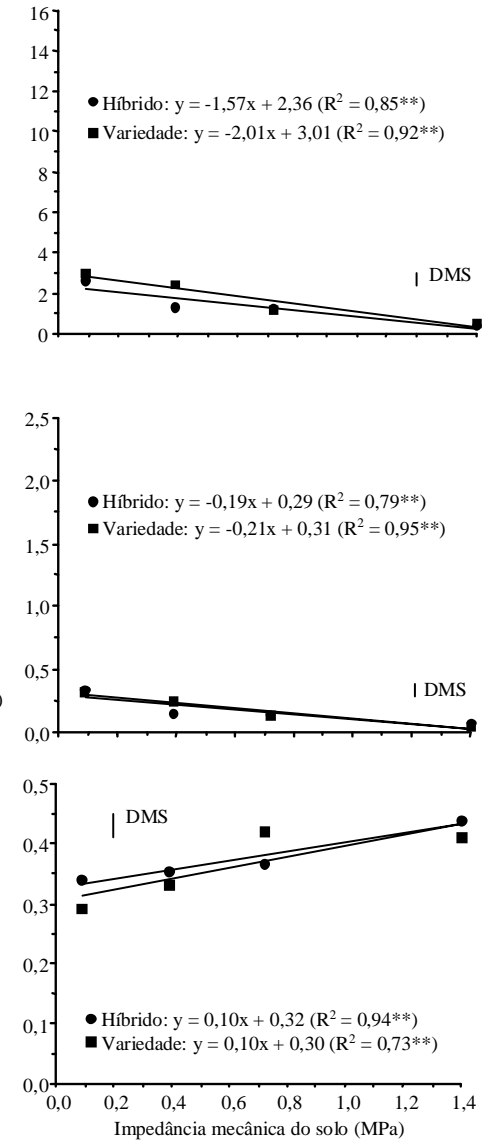

Camada inferior
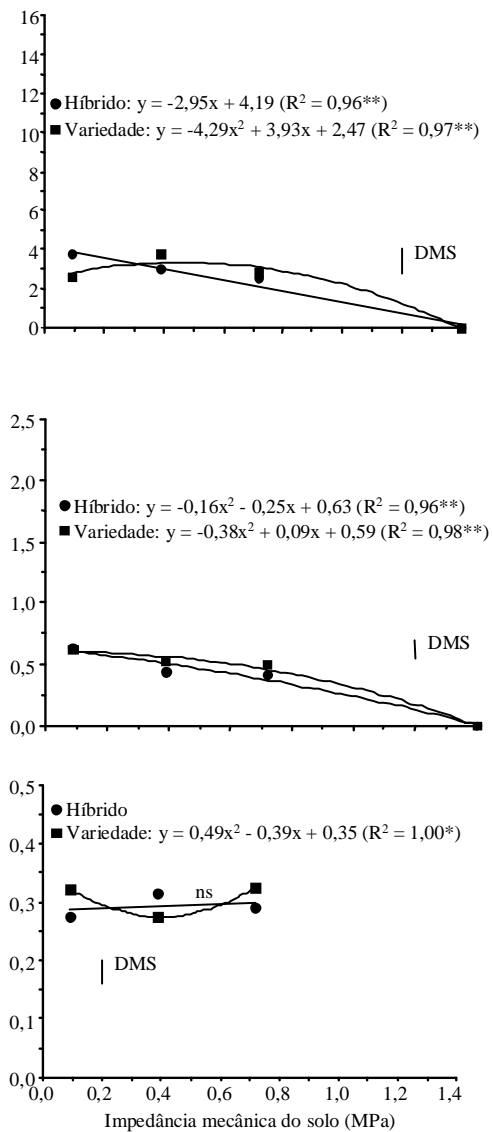

Figura 2. Densidade do comprimento radicular, massa da matéria seca de raízes e diâmetro médio radicular das plantas de milho, nas camadas superior, compactada e inferior dos vasos, em função da impedância mecânica do solo. DMS: diferença mínima significativa pelo teste t, a 5\% de probabilidade. ${ }^{\text {ns }}$ Não-significativo. $* \mathrm{e}^{* *}$ Significativo a $5 \%$ e a $1 \%$ de probabilidade, respectivamente. 
compactada. O resultado apresentado é condizente com os relatos de Materechera et al. (1992) e Russel \& Goss (1974), pois o diâmetro médio radicular das plantas de milho aumentou à medida que o crescimento das raízes na camada do solo compactado foi reduzido. Segundo Camargo \& Alleoni (1997), a pressão exercida pela raiz contra um agente rígido externo é chamada de pressão de crescimento, que depende da pressão de turgor das células em processo de alongamento e da área de contato da raiz no plano em que a força é aplicada. Portanto, o engrossamento das raízes das plantas de milho na camada compactada pode ser um indicativo de que esta espécie tem pouco potencial para estabelecer o seu sistema radicular em solos compactados. No trabalho de Müller et al. (2001), apesar do diâmetro radicular de algumas gramíneas ter aumentado com o aumento da compactação do solo, as espécies que apresentaram mais sucesso no crescimento radicular dentro da camada de solo compactado, de uma maneira geral, foram aquelas que tiveram menor diâmetro médio de raízes.

O diâmetro médio radicular das plantas de milho variou significativamente abaixo da camada de solo compactado, porém, de maneira aleatória e não manteve proporcionalidade com os níveis de impedância mecânica do solo utilizados no experimento (Figura 2).

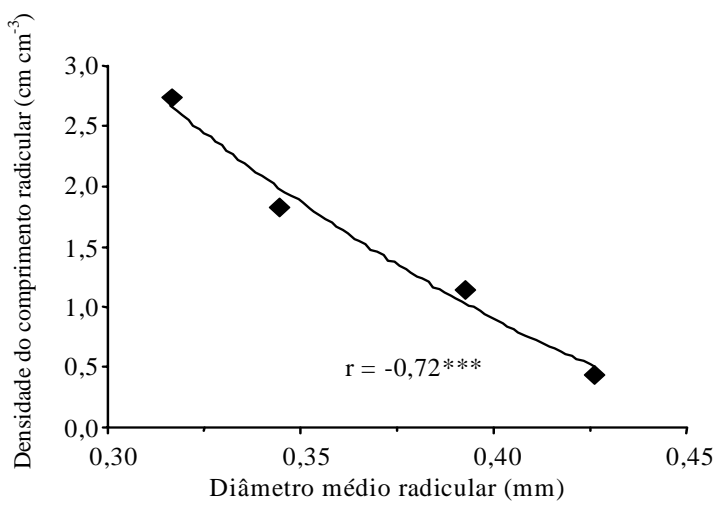

Figura 3. Correlação entre as variáveis diâmetro médio radicular e densidade do comprimento radicular das plantas de milho na camada de solo compactado. ***Significativo a $0,1 \%$ de probabilidade pelo teste $\mathrm{t}$.
O sistema radicular do milho mostrou-se sensível à compactação do solo, independentemente de ser um híbrido desenvolvido para cultivos com alta tecnologia ou uma variedade recomendada para situações de baixo investimento. Por isso, torna-se necessário que se faça um diagnóstico prévio das condições físicas do solo de áreas onde se pretende cultivar milho pois, muito provavelmente, a restrição física ao desenvolvimento radicular pode proporcionar prejuízos ao desenvolvimento da cultura.

\section{Conclusões}

1. A cultivar de milho híbrido AG-5011 e a variedade Sol da Manhã, tanto no crescimento aéreo como no crescimento radicular, são igualmente prejudicadas pela compactação do solo.

2. O impedimento físico em subsuperfície altera a distribuição do sistema radicular das plantas de milho ao longo do perfil do solo, porém, não diminui a produção total de raízes.

3. Uma camada compactada com resistência à penetração da ordem de 1,4 MPa impede que o sistema radicular do milho atravesse essa camada e se desenvolva em profundidade.

4. O diâmetro médio radicular das plantas de milho apresenta alta correlação com o desenvolvimento das raízes dentro da camada de solo compactado.

\section{Referências}

BENNIE, A. T. P. Growth and mechanical impedance. In: WAISEL, Y.; ESHEL, A.; KAFKAFI, U. Plant roots. $2^{\text {nd }}$ ed. New York: M. Dekker, 1996. p. 453-470.

CAMARGO, O. A.; ALLEONI, L. R. F. Compactação do solo e o desenvolvimento das plantas. Piracicaba: Esalq, 1997. 132 p.

CARVALHO, W. A.; ESPINDOLA, C. R.; PACCOLA, A. A. Levantamento de solos da Fazenda Lageado-Estação Experimental "Presidente Médici". Botucatu: Unesp, 1983. 95 p.

DEXTER, A. R. Mechanics of root growth. Plant and Soil, Dordrecht, v. 98, n. 3, p. 303-312, 1987.

EMBRAPA. Centro Nacional de Pesquisa de Solos. (Rio de Janeiro, RJ). Manual de métodos de análise de solo. 2. ed. Rio de Janeiro, 1997. 212 p. 
EMBRAPA. Centro Nacional de Pesquisa de Solos (Rio de Janeiro, RJ). Sistema brasileiro de classificação de solos. Brasília: Embrapa-SPI/Embrapa-CNPS, 1999. $412 \mathrm{p}$.

FOLONI, J. S. S. Crescimento radicular da soja (Glycine max (L.) Merrill) e de cinco adubos verdes em função da compactação do solo. 1999. 73 f. Dissertação (Mestrado em Agricultura) - Universidade Estadual Paulista, Botucatu, 1999.

GEDIGA, K. Influence of subsoil compaction on the uptake of ${ }^{45} \mathrm{Ca}$ from the soil profile and on maize yield. Soil and Tillage Research, Amsterdam, v. 19, n. 2, p. 351355,1991

GUPTA, S. C.; ALLMARAS, R. R. Models to access the susceptibility of soil to excessive compaction. Advances in Soil Sciences, New York, v. 6, p. 65-100, 1987.

HATANO, R.; IWANAGA, K.; OKAJIMA, H.; SAKUMA, T. Relationship between the distribution of soil macropores and root elongation. Soil Science and Plant Nutrition, Tokyo, v. 34, n. 4, p. 535-546, 1988.

MATERECHERA, S. A.; ALSTON, A. M.; KIRBY, J. M.; DEXTER, A. R. Influence of root diameter on the penetration of seminal roots into a compacted subsoil. Plant and Soil, Dordrecht, v. 144, p. 297-303, 1992.

MÜLlER, M. M. L.; CECCON, G.; ROSOLEM, C. A. Influência da compactação do solo em subsuperfície sobre o crescimento aéreo e radicular de plantas de adubação verde de inverno. Revista Brasileira de Ciência do Solo, Viçosa, MG, v. 25, p. 531-538, 2001.

PASSIOURA, J. B. Soil structure and plant growth. Australian Journal of Soil Research, Collingwood, v. 29, p. 717-728, 1991.

PATERNIANI, E. Métodos tradicionais de melhoramento do milho. In: BÜLL, L. T.; CANTERELLA, H. Cultura do milho: fatores que afetam a produtividade. Piracicaba: Potafos, 1993. p. 23-42.

PIMENTEL-GOMES, F. Curso de estatística experimental. 13. ed. Piracicaba: Nobel, 1990. 468 p.
RAIJ, B. van; QUAGGIO, J. A. Métodos de análise de solo para fins de fertilidade. Campinas: Instituto Agronômico, 1983. 170 p. (Boletim Técnico, 81).

ROSOLEM, C. A. Relações solo-planta na cultura do milho. Jaboticabal: Funep, 1995. 53 p.

ROSOLEM, C. A.; ALMEIDA, A. C. da S.; SACRAMENTO, L. V. S. do. Sistema radicular e nutrição da soja em função da compactação do solo. Bragantia, Campinas, v. 53, p. 259-266, 1994a.

ROSOLEM, C. A.; FOLONI, J. S. S.; TIRITAN, C. S. Root growth and nutrient accumulation in cover crops as affected by soil compaction. Soil and Tillage Research, Amsterdam, v. 65, p. 109-115, 2002.

ROSOLEM, C. A.; VALE, L. S. R.; GRASSE, H. F.; MORAES, M. H. de. Sistema radicular e nutrição do milho em função da calagem e da compactação do solo. Revista Brasileira de Ciência do Solo, Viçosa, MG, v. 18, p. 491-497, 1994b.

RUSSEL, R. S.; GOSS, M. J. Physical aspects of soil fertility: the response of roots to the mechanical impedance. Netherlands Journal of Agricultural Science, Wageningen, v. 22, p. 305-318, 1974.

SILVA, A. P.; TORMENA, C. A.; IMHOFF, S. Intervalo hídrico ótimo. In: MORAES, M. H.; MÜLLER, M. M. L.; FOLONI, J. S. S. Qualidade física do solo: métodos de estudo-sistemas de preparo e manejo do solo. Jaboticabal: Funep, 2002. p. 1-18.

SILVA, B. G. da; CORRÊA, L. A. Cultivares de milho. Informe Agropecuário, Belo Horizonte, v. 14, p. 13-14, 1990.

SILVA, R. H.; ROSOLEM, C. A. Crescimento radicular de espécies utilizadas como cobertura decorrente da compactação do solo. Revista Brasileira de Ciência do Solo, Viçosa, MG, v. 25, p. 253-260, 2001.

TAYLOR, H. M.; BRAR, G. S. Effect of soil compaction on root development. Soil and Tillage Research, Amsterdam, v. 19, p. 111-119, 1991. 